\title{
Polyethylene glycol versus sodium picosulfalte bowel preparation in the setting of a colorectal cancer screening program
}

\author{
Omar Kherad MD MPH${ }^{1 *}$, Sophie Restellini $\mathrm{MD}^{2 *}$, Myriam Martel Bsc ${ }^{3}$, Alan N Barkun MD MSc $\mathrm{MS}^{3,4}$
}

O Kherad, S Restellini, M Martel, A Barkun. Polyethylene glycol versus sodium picosulfate bowel preparation in the setting of a colorectal cancer screening program. Can J Gastroenterol Hepatol 2015;29(7):384-390.

BACKGROUND: Adequate bowel preparation for colonoscopy is an important predictor of colonoscopy quality.

OBJECTIVE: To determine the difference in terms of effectiveness between different existing colon cleansing products in the setting of a colorectal cancer screening program.

METHODS: The records of consecutive patients who underwent colonoscopy at the Montreal General Hospital (Montreal, Quebec) between April 2013 and April 2014 were retrospectively extracted from a dedicated electronic digestive endoscopic institutional database.

RESULTS: Overall, 2867 charts of patients undergoing colonoscopy were assessed, of which 1130 colonoscopies were performed in a screening setting; patients had adequate bowel preparation in $90 \%$. Quality of preparation was documented in only $61 \%$. Bowel preparation was worse in patients receiving sodium picosulfate (PICO) alone compared with polyethylene glycol, in a screening setting (OR 0.3 [95\% CI 0.2 to 0.6$]$ ). Regardless of the preparation type, the odds of achieving adequate quality cleansing was 6.6 for patients receiving a splitdose regimen (OR 6.6 [95\% CI 2.1 to 21.1]). In multivariable analyses, clinical variables associated with inadequate bowel preparation in combined population were use of PICO, a nonsplit regimen and inpatient status. The polyp detection rate was very high (45.6\%) and was correlated with withdrawal time.

CONCLUSION: Preparation quality needs to be more consistently included in the colonoscopy report. Split-dose regimens increased the quality of colon cleansing across all types of preparations and should be the preferred method of administration. Polyethylene glycol alone provided better bowel cleansing efficacy than PICO in a screening setting but PICO remains an alternative in association with an adjuvant.

Key Words: Bowel preparation; Colonoscopy; Quality; Screening setting

\author{
Une préparation intestinale de polyéthylèneglycol \\ comparée à celle de picosulfate de sodium dans un \\ programme de dépistage du cancer colorectal
}

\begin{abstract}
HISTORIQUE : Une bonne préparation intestinale en vue de la coloscopie est un important prédicteur de la qualité de l'intervention.

OBJECTIF : Déterminer la différence d'efficacité entre divers produits de nettoyage du côlon dans le cadre d'un programme de dépistage du cancer colorectal.

MÉTHODOLOGIE : Les chercheurs ont examiné les patients consécutifs qui ont subi une coloscopie à l'Hôpital général de Montréal, au Québec, entre avril 2013 et avril 2014. Ils les ont extraits d'une base de données rétrospective de l'établissement consacrée aux endoscopies digestives.
\end{abstract}

RÉSULTATS : Les chercheurs ont évalué le dossier de 2867 patients qui avaient subi une coloscopie, dont 1130 dans le cadre d'un dépistage. Au total, $90 \%$ des patients avaient eu une bonne préparation coloscopique. La qualité de la préparation n'était consignée que chez $61 \%$ des patients. La préparation intestinale était moins bonne chez les patients qui avaient reçu du picosulfate de sodium (PICO) seul au lieu du polyéthylèneglycol dans le cadre du dépistage (rapport de cotes [RC] 0,3 [95\% IC 0,2 à $0,6]$ ). Quel que soit le type de préparation, la possibilité d'obtenir un nettoyage de bonne qualité était 6,6 fois plus élevée chez les patients qui recevaient une dose divisée (RC 6,6 [95 \% IC 2,1 à 21,1]). Dans les analyses multivariables, les variables cliniques associées à une préparation intestinale inadéquate dans une population combinée étaient l'utilisation de PICO, l'administration en une seule dose et l'hospitalisation. Le taux de dépistage de polypes, très élevé $(45,6 \%)$, était corrélé avec le délai d'attente.

CONCLUSION : Il faut consigner plus systématiquement la qualité des préparations dans le rapport de coloscopie. La division des doses accroît la qualité du nettoyage du côlon dans tous les types de préparation et devrait être favorisée. L'efficacité du nettoyage intestinal par le polyéthylèneglycol seul était préférable au PICO dans un cadre de dépistage, mais le PICO demeure une solution s'il s'associe à un adjuvant.
C olorectal cancer (CRC) is the third most common cancer in the world, with nearly 1.4 million new cases diagnosed in 2012, and one of the leading causes of death from cancer in Canada and worldwide (1-3). CRC screening has the potential for being the most cost-effective cancer screening in terms of both prevention and early detection (4).

There exist no convincing data establishing the superiority of any one colon cleansing product over another, with conflicting summary data in the literature as summarized in a recent meta-analysis (5). It appears that some of these products are generally well tolerated according, in part, to patient characteristics. Following black boxing, and in some jurisdictions withdrawal of sodium phosphate due to rare but significant renal toxicity (6), two of the main products that share the market in Canada include polyethylene glycol (PEG) and a preparation of sodium picosulfate plus magnesium oxide (PICO).

PEG preparations have long been proven safe and efficacious (7-9); however, the main issue with PEG is its relatively low patient adherence, mainly due to its taste and the large volume patients must consume ( $3 \mathrm{~L}$ to $4 \mathrm{~L}$ ). It has been estimated that at least $5 \%$ to $15 \%$ of patients do not complete the preparation due to the large volume and/or poor palatability (10). As an alternative, low-volume

\footnotetext{
*Authors who contributed equally

${ }^{1}$ Internal Medicine Department, La Tour Hospital and University of Geneva; ${ }^{2}$ Department of specilaties of Internal Medicine, Divison of Gastroenterology, Geneva University Hospital, Geneva, Switzerland; ${ }^{3}$ Division of Gastroenterology; ${ }^{4}$ Department of Epidemiology and Biostatistics and Occupational Health, McGill University Health Centre, McGill University, Montreal, Quebec

Correspondence: Dr Alan N Barkun, Division of Gastroenterology, The McGill University Health Centre, Montreal General Hospital site, 1650 Cedar

Avenue, Room D16.125, Montreal, Quebec H3G 1A4. Telephone 514-934-8309, fax 514-834-8531, e-mail alan.barkun@muhc.mcgill.ca Received for publication January 22, 2015. Accepted May 18, 2015
} 
hyperosmolar preparations have recently emerged. PICO has been approved in Canada since 2004 and in the United States since 2012. The dual-action bowel cleansing preparation containing sodium picosulfate and magnesium citrate acts as both stimulant and osmotic laxative to clean the colon. Compared with sodium phosphate, PICO revealed comparable cleansing efficacy but with better tolerance (11), while its comparative efficacy with PEG remains unclear with conflicting results $(8,12-14)$.

Regardless of the type of preparation, splitting the volume over two days appears to be more effective and improves tolerance (15). The superiority of split-dosing may relate to the shortened interval of time between the last intake of preparation product and the colonoscopy (16). Aligned with this theory, the European Society of Gastrointestinal Endoscopy and the US Multi-Society Task Force (US MSTF) on CRC recommend a split-dose regimen for morning colonoscopy and a sameday regimen for afternoon colonoscopy $(17,18)$.

To the best of our knowledge, the comparative effectiveness of these different preparations in a specific population screening program setting is not known. Of note, the need for repeat procedures because of a poor preparation carries a significant cost burden, especially in the context of a population-based CRC screening program with limited resource availability and may affect the subsequent uptake of colonoscopy in healthy individuals (19). It was, therefore, necessary to identify the optimal bowel preparation in terms of effectiveness in a 'real life' setting, to make recommendations for the optimal future deployment of the Quebec Ministry of Health and Social Services population-based CRC provincial screening program (PQDCCR). The Montreal General Hospital, site of the McGill University Health Centre (MUHC-MGH, Montreal, Quebec) has been chosen as a pilot site to ensure the performance of colonoscopies follows established standards of care before full program deployment; therefore, we reviewed colon preparation performances of patients undergoing a screening colonoscopy on this site.

The primary objective of the present study was to assess bowel cleanliness after different existing colonoscopy preparations in a cancer screening program setting. We also aimed to identify independent predictors of inadequate bowel preparation and polyp detection rate (PDR) by assessing different indicators, in addition to colonic preparations, such as age, sex, American Society of Anesthesiologists (ASA) score, patient status (inpatient versus outpatient) and indication for colonoscopy.

\section{METHODS}

A cross-sectional study using an anonymized endoscopic electronic database, including consecutive patients referred for colonoscopy, was conducted. The MUHC-MGH is a tertiary care institution with a fiveroom endoscopy unit staffed by 12 medical and surgical endoscopists, performing $>6500$ colonoscopies yearly. All patients receive an information sheet on colon cancer screening, colonoscopy and specific bowel preparation instructions beforehand, while consent is obtained by the endoscopist on the day of the procedure. Endoscopists use a commercial computerized endoscopic report generator (Endoworks, Olympus Inc, USA) modified to fulfill PQDCCR-recommended quality indicator collection (20). For the purpose of the present study, the corresponding endoscopic patient database over a one-year period spanning April 2013 to April 2014 was accessed. The records of consecutive patients were retrospectively extracted and analyzed when the type of products for the bowel preparation was documented. Also tracked were several validated preprocedural, intraprocedural and postprocedural quality indicators. The study protocol was approved by an independent ethics committee.

\section{Definition}

Quality indicators extracted were separated as follows: preprocedural indicators (appropriate indication, colonic preparation, clinical characteristics [sex, age, ASA score, inpatients]); intraprocedural indicators (bowel preparation quality, rates of cecal intubation, PDR, colonoscopy withdrawal time); and postprocedure indicators (completeness of colonoscopy and complication rates including perforation and bleeding).

The primary outcome was preparation adequacy. At colonoscopy, gastroenterologists at the $\mathrm{MGH}$ assess colonic cleaning using the following modified validated scale recommended by the PQDCCR, which is a modification of the Aronchick scale (21): excellent - no fecal matter or nearly none in the colon, small to moderate amounts of liquid easily suctioned; good - no fecal matter or nearly none in the colon, large amounts of liquid easily suctioned; fair - some semisolid stool that could be suctioned or washed away with difficulty; and poor semisolid stool that could not be suctioned or washed away, complete colonoscopy impossible

According to the established criteria, bowel preparations were classified as 'excellent' or 'good' for the procedure to be considered valid and meet the criteria of an adequate preparation (the definition was embedded in the reporting system, providing point-of-care referencing). A pre-planned dichotomization was performed by grouping excellent or good bowel preparation versus fair, poor (ie, excellent or good $=$ adequate versus fair or poor $=$ inadequate preparation $)$, consist ent with US MSTF operational recommendations (18).

'Screening indication' was defined as a colonoscopy performed for subjects without any symptoms who are at average or high risk for colonic cancer. Colonoscopy performed after immunochemical fecal occult blood test was also considered to be a 'screening indication'.

Different regimens of colon cleansing product groups were compared in terms of efficacy and reported as follows: PEG versus others; PEG versus PICO; split versus non split; PEG split versus PEG non split; all preparations + adjuvant versus all preparations; PEG + adjuvant versus PEG; and PICO + adjuvant versus PICO.

Adjuvants reported were magnesium $(\mathrm{Mg})$ citrate or bisacodyl. Of note, PICO used at MGH already contains $\mathrm{Mg}$ citrate. Therefore, $\mathrm{PICO}+\mathrm{Mg}$ citrate means addition of $\mathrm{Mg}$ citrate to a pre-existing $\mathrm{PICO}+\mathrm{Mg}$ citrate solution.

\section{Statistical analyses}

Descriptive variables are presented as means \pm SDs for continuous variables and proportions with 95\% CIs for categorical variables. Inferential testing was performed using $\chi^{2}$ tests, Fischer's tests or $t$ tests, where appropriate. The effect of different colon cleansing product groups on preparation adequacy was first examined by performing an unadjusted analysis, using $\chi^{2}$ testing. Results are reported with ORs and $95 \%$ Cls. The product group/preparation adequacy association was then stratified according to each potential available confounder in turn (age, sex, indication of colonoscopy, ASA score, inpatient), allowing the assessment of potential effect modifiers and confounding at this stage. If no significant heterogeneity was detected among strata, a pooled Mantel-Haenszel OR for preparation adequacy comparing cleansing product group was produced and compared with the crude OR to assess the extent of confounding in a table. Multiple logistic regressions of outcomes on combinations of potential risk factors were performed with variables selected through forward fitting. Likelihood ratio tests were performed to assess the goodness of fit of different models.

Separate multivariable regression analyses were performed to adjust for all potential confounders and to identify potential independents predictors for an inadequate bowel preparation and PDR. For both analyses, stratified analysis according to the indication was performed. The software used for all statistical computations was SPSS version 20.0 (IBM Corporation, USA).

\section{Sample size}

Assuming a satisfactory rate of $90 \%$, the estimated number of 3000 participants was significantly higher than the 213 patients needed per colonoscopic preparation group to reach $80 \%$ power to detect a between-group difference in efficacy of $10 \%$ at a two-sided significance level of 0.05 . 
TABLE 1

Patient characteristics and procedure description

\begin{tabular}{|c|c|c|c|c|c|}
\hline & $\begin{array}{c}\text { Missing, } \\
\mathrm{n}\end{array}$ & $\begin{array}{c}\text { Overall } \\
(n=2867)\end{array}$ & $\begin{array}{c}\text { Screening } \\
(n=1130)\end{array}$ & $\begin{array}{c}\text { Non- } \\
\text { screening } \\
(n=1737)\end{array}$ & $\mathbf{P}^{*}$ \\
\hline \multicolumn{6}{|c|}{ Patient characteristics } \\
\hline $\begin{array}{l}\text { Age, years, } \\
\text { mean } \pm \text { SD }\end{array}$ & 17 & $60.4 \pm 13.5$ & $59.5 \pm 9.9$ & $61.0 \pm 15.4$ & $<0.01$ \\
\hline $18-25$ & & $39(1.4)$ & $0(0)$ & $39(2.3)$ & $<0.01$ \\
\hline $25-50$ & & $498(17.5)$ & $156(13.9)$ & $342(19.8)$ & \\
\hline $50-75$ & & $1927(67.6)$ & $900(80.1)$ & $1027(59.5)$ & \\
\hline$>75$ & & $386(13.5)$ & $68(6.0)$ & $318(18.4)$ & \\
\hline Male sex & 11 & $1432(50.1)$ & $579(51.4)$ & $853(49.3)$ & 0.3 \\
\hline Inpatients & & $108(3.8)$ & $0(0)$ & $108(6.2)$ & $<0.01$ \\
\hline $\begin{array}{l}\text { ASA score } \\
\text { mean } \pm \text { SD }\end{array}$ & 468 & $1.42 \pm 0.52$ & $1.34 \pm 0.47$ & $1.47 \pm 0.54$ & $<0.01$ \\
\hline ASA 1 & & $1414 \pm 58.9$ & $602 \pm 65.8$ & $812 \pm 54.7$ & $<0.01$ \\
\hline ASA 2 & & $953 \pm 39.7$ & $312 \pm 34.1$ & $641 \pm 43.2$ & \\
\hline ASA 3 & & $31 \pm 1.3$ & $1 \pm 0.1$ & $30 \pm 2.0$ & \\
\hline ASA 4 & & $1 \pm 0.1$ & $0 \pm 0$ & $1 \pm 0.1$ & \\
\hline \multicolumn{6}{|c|}{ Procedure description } \\
\hline $\begin{array}{l}\text { Type of bowel } \\
\text { preparation }\end{array}$ & 0 & & & & \\
\hline PEG & & $1720(60)$ & $633(56.0)$ & $1087(62.6)$ & $<0.01$ \\
\hline PICO & & 1124 (39.2) & 496 (43.9) & $628(36.2)$ & \\
\hline Enema & & $20(0.7)$ & $0(0)$ & $20(1.2)$ & \\
\hline Adjuvants alone & & $3(0.1)$ & $1(0.1)$ & $2(0.1)$ & \\
\hline Use of adjuvants & & $368(12.8)$ & $158(14.0)$ & $210(12.1)$ & 0.1 \\
\hline $\mathrm{PEG}+\mathrm{Mg}$ citrate & & $121(4.2)$ & $63(5.6)$ & $58(3.3)$ & 0.1 \\
\hline $\mathrm{PICO}+\mathrm{Mg}$ citrate & & $238(8.3)$ & $91(8.1)$ & $147(8.5)$ & \\
\hline PEG + bisacodyl & & $4(0.1)$ & $2(0.2)$ & $2(0.1)$ & \\
\hline PICO + bisacodyl & & $5(0.2)$ & $2(0.2)$ & $3(0.2)$ & \\
\hline Split regimen & 579 & $119(4.2)$ & $55(6.2)$ & $64(4.6)$ & 0.1 \\
\hline $\begin{array}{l}\text { Quality of } \\
\text { preparation }\end{array}$ & 1100 & & & & \\
\hline Documented & & $1767(61.6)$ & $748(66.2)$ & 1019 (58.6) & \\
\hline Adequate & & $1484(84.0)$ & $672(89.8))$ & $812(79.7)$ & $<0.01$ \\
\hline $\begin{array}{l}\text { Withdrawal time, } \\
\text { min, mean } \pm \text { SD }\end{array}$ & 1478 & $9.4 \pm 4.3$ & $9.76 \pm 4.4$ & $9.20 \pm 4.2$ & 0.02 \\
\hline Polyp detection rate & 0 & $1255(43.8)$ & $515(45.6)$ & $740(42.6)$ & 0.1 \\
\hline Cecal intubation & 57 & $2699(96.0)$ & $1071(96.1)$ & $1628(96.0)$ & 0.8 \\
\hline Complication & 1 & $13(0.5)$ & $4(0.4)$ & $9(0.5)$ & 0.5 \\
\hline
\end{tabular}

Data presented as $n$ (\%) unless otherwise indicated. ${ }^{*}$ Comparisons made between the screening and non-screening setting: $\chi^{2}$ test, Fischer test and test analyses. ASA American Society of Anesthesiology; Mg Magnesium; PEG Polyethylene glycol; PICO Sodium picosulfate

\section{RESULTS}

Patients' characteristics and procedure description

A total of 6304 colonoscopies were performed at the MUHC-MGH from April 1, 2013 to April 30, 2014. Colonoscopies for which the type of bowel preparation was not identified $(n=3437)$ were excluded, leaving 2867 colonoscopies for 2730 patients $(50.1 \%$ men, mean age 60.4 years, $96.2 \%$ outpatients). Of note, colonoscopy indications and patient characteristics (age and sex) did not differ in the excluded group.

Most (67.6\%) patients were between 50 and 75 years of age, without significant acute illness as expressed by the mean ASA score $<2$ (Table 1). Colonoscopies were performed in a screening setting in 1130 patients (39.4\%) versus 1737 (60.6\%) for other indications. The indications for a colonoscopy performed outside the screening setting are described in Figure 1. In an analysis restricted to endoscopy for screening, patients characteristics differed significantly compared with the nonscreening group because patients were younger (mean $[ \pm \mathrm{SD}$ ] age $59.5 \pm 9.9$ versus $61 \pm 15.4$ years; $\mathrm{P}<0.01$ )

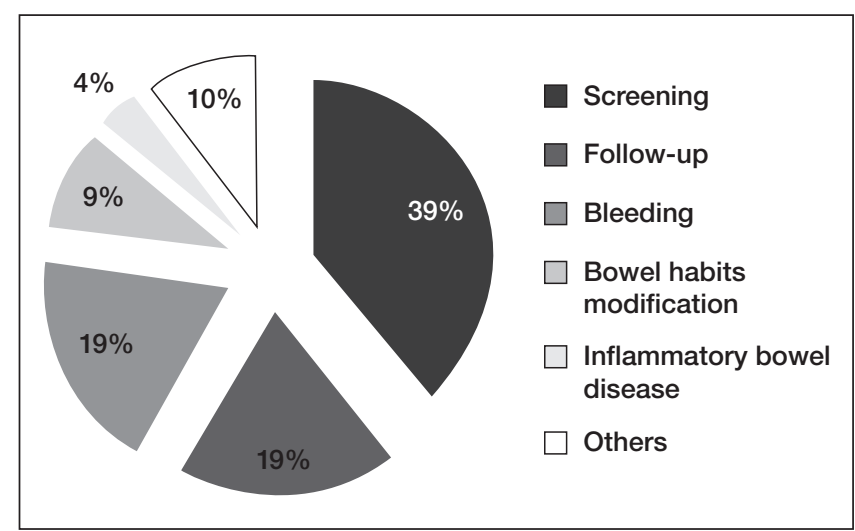

Figure 1) Indications for colonoscopy

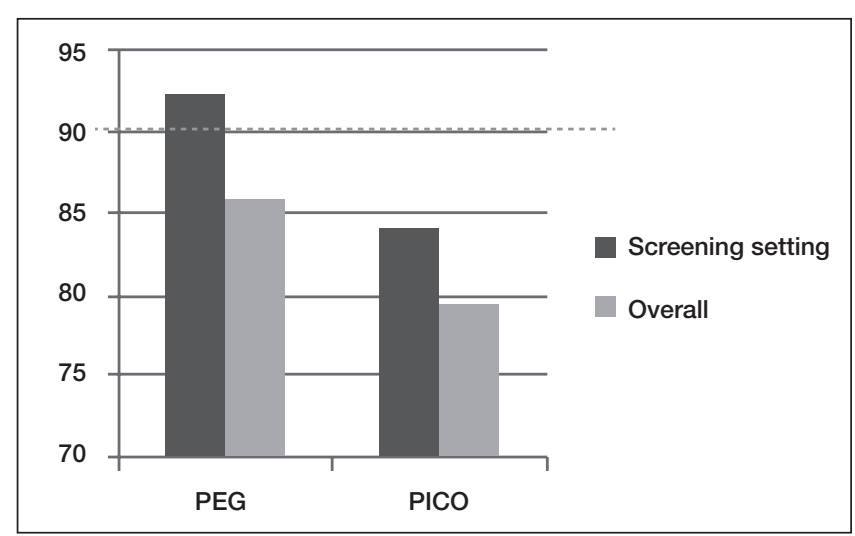

Figure 2) Percentage of adequate preparation with the two most commonly used preparations in screening setting and overall. PEG Polyethylene glycol; PICO Sodium picosulfate

and in better health (mean ASA score $1.34 \pm 0.47$ versus $1.47 \pm 0.54$; $\mathrm{P}<0.01$ ) (Table 1).

The two most commonly used products both overall and in the screening setting were PEG- and PICO-based preparations $(60 \%$ and $39.2 \%$, respectively, overall, and $56.1 \%$ and $43.9 \%$, respectively, for a screening indication). Adjuvant and split-dose regimens were used more rarely $(12.8 \%$ and $4.2 \%$, respectively). Colonoscopies were completed and the cecum intubated in $96 \%$, with a complication rate of $0.5 \%$.

\section{Quality of preparation}

Overall, quality of preparation was adequate in $84 \%$, reaching $89.8 \%$ in the screening setting. Of note, the quality of preparation was documented in only $61.6 \%$. The crude effectiveness of PEG and PICO overall and in the screening setting are depicted in Figure 2.

Head-to-head comparisons of different products and regimens are shown in Table 2 in crude analysis and after adjustment for the previously identified confounders in turn (ASA score, sex, age, indication), with no effect modifiers detected at this stage. Bowel preparation was worse in patients receiving PICO compared with PEG, even after adjustment for ASA score, sex, age and indication of colonoscopy (OR 0.3 [95\% CI 0.2 to 0.4]) (Table 3). A similar finding was noted when restricting the analysis to screening indications (OR 0.3 [95\% CI 0.2 to 0.6$]$ ). Overall, PEG in a split-dosing regimen yielded significantly greater proportions of patients with adequate preparations (OR 7.0 [95\% CI 1.7 to 29.1]). Split-dose regimens, regardless of the product used and the indication of colonoscopy, achieved better quality preparation in the overall population (OR 6.6 [95\% CI 2.1 to 21.1]), with a trend noted in colonoscopies for screening indications (OR 5.8 [95\% CI 0.8 to 43.6]) ( $\mathrm{P}=0.08)$ (Table 3$)$. There were no clinically relevant differences in bowel preparation between regimens with use 


\begin{tabular}{|c|c|c|}
\hline Bowel preparation & $\begin{array}{c}\text { Overall } \\
\text { OR* }^{*}(95 \% \mathrm{Cl})\end{array}$ & $\begin{array}{l}\text { Screening setting } \\
\mathrm{OR}^{*}(95 \% \mathrm{Cl})\end{array}$ \\
\hline PEG versus others & $1.2(0.9-1.5)$ & $1.8(1.1-2.8)$ \\
\hline Adjusted for ASA score & $1.4(1.1-1.9)$ & $1.9(1.1-3.4)$ \\
\hline Adjusted for sex & $1.2(0.0-1.5)$ & $1.8(1.1-3.0)$ \\
\hline Adjusted for age & $1.2(0.9-1.5)$ & $1.8(1.1-2.9)$ \\
\hline Adjusted for indication & $1.2(0.9-1.6)$ & - \\
\hline PICO versus PEG & $0.6(0.5-0.8)$ & $0.5(0.3-0.7)$ \\
\hline Adjusted for ASA score & $0.3(0.2-0.4)$ & $0.2(0.2-0.4)$ \\
\hline Adjusted for sex & $0.6(0.5-0.8)$ & $0.5(0.4-0.7)$ \\
\hline Adjusted for age & $0.6(0.4-0.8)$ & $0.5(0.4-0.7)$ \\
\hline Adjusted for indication & $0.5(0.4-0.7)$ & - \\
\hline Split versus nonsplit & $6.6(2.0-21.0)$ & $6.0(0.8-44.4)$ \\
\hline Adjusted for ASA score & $6.7(2.1-21.6)$ & $5.8(0.8-44.7$ \\
\hline Adjusted for sex & $6.4(2.0-20.4)$ & $5.7(0.8-41.8)$ \\
\hline Adjusted for age & $6.6(2.0-21.0)$ & $6.1(0.8-45.4)$ \\
\hline Adjusted for indication & $6.7(2.1-21.5)$ & - \\
\hline PEG split versus PEG & $7.9(1.9-32.6)$ & $\dagger$ \\
\hline Adjusted for ASA score & $7.0(1.7-28.9)$ & \\
\hline Adjusted for sex & $7.8(1.9-32.1)$ & \\
\hline Adjusted for age & $7.9(1.9-32.4)$ & \\
\hline Adjusted for indication & $8.0(1.9-33.6)$ & - \\
\hline PICO + adjuvants versus PICO & $2.1(1.3-3.5)$ & $2.4(1.0-5.8)$ \\
\hline Adjusted for ASA score & $0.9(0.3-2.8)$ & $2.2(0.2-20.6)$ \\
\hline Adjusted for sex & $2.1(1.3-3.5)$ & $2.4(1.0-5.7)$ \\
\hline Adjusted for age & $2.1(1.3-3.6)$ & $2.5(1.0-59)$ \\
\hline Adjusted for indication & $2.2(1.3-3.8)$ & - \\
\hline
\end{tabular}

Statistical analysis: $\chi^{2}$ analysis. ${ }^{*} C r u d e$ and Mantel Haenszel OR reported after testing homogeneity of strata; ${ }^{\dagger}$ No subject received the preparation in one group. ASA American Society of Anesthesiology; PEG Polyethylene glycol; PICO Sodium picosulfate; Split Split-dose regimen

of adjuvants, except for PICO, which yielded significantly greater proportions of patients with adequate preparartions in both the combined population and screening settings (OR 2.1 [95\% CI 1.3 to 3.5], and OR 2.4 [95\% CI 1.0 to 5.8], respectively).

Independent predictors of inadequate bowel preparation in the combined population are described in Table 4. In addition to PICO product use and non-split-dose regimen, other predictors of inadequate preparation in multivariable analysis were inpatient and indication of colonoscopy (Table 4). Bowel preparation was lowest in patients referred for bleeding and bowel habits modification.

In the screening setting, the sole independent predictor of inadequate bowel preparation was the use of PICO (Table 5). In multivariable analysis, use of PICO remained independently and significantly predictive, yielding significantly greater proportions of patients with inadequate preparations compared with PEG (OR 7.4 [95\% CI 4.3 to 12.6$])$.

\section{PDR}

PDR was high $(43.8 \%)$, and even higher in the screening setting $(45.6 \%)$ with age $>75$ years, male sex, ASA score and indication of colonoscopy as significant preprocedural indicator predictors in univariable analysis (Tables 6 and 7).

PDR was not associated with quality of preparation; however, PDR was associated with withdrawal time. The odds of detecting a polyp was three times higher when withdrawal time was $>6 \mathrm{~min}$ in both the combined population and screening setting (OR 2.8 [95\% CI 1.9 to 4.2, and OR 3.3 [95\% CI 1.7 to 6.6], respectively) even in multivariable analysis after adjustment for quality of preparation, age, ASA score and indication for colonoscopy (Tables 6 and 7).
TABLE 3

Multivariable analysis of different bowel preparations in terms of quality of preparation in screening setting and overall

\begin{tabular}{llrlr}
\hline & $\begin{array}{c}\text { Overall } \\
\text { OR }^{*}(\mathbf{9 5 \%} \mathrm{Cl})\end{array}$ & $\mathbf{P}$ & \multicolumn{1}{c}{$\begin{array}{c}\text { Screening } \\
\mathrm{OR}^{\dagger}(\mathbf{9 5} \% \mathrm{Cl})\end{array}$} & $\mathbf{P}$ \\
\hline PICO vs PEG & $0.3(0.2-0.4)$ & $<0.01$ & $0.3(0.2-0.6)$ & $<0.01$ \\
$\begin{array}{c}\text { Split regimen vs } \\
\text { non split }\end{array}$ & $6.6(2.1-21.1)$ & $<0.01$ & $5.8(0.8-43.6)$ & 0.08 \\
& & & &
\end{tabular}

${ }^{*}$ Adjusted for American Society of Anesthesiology (ASA), sex, age, indication; ${ }^{\dagger}$ Adjusted for ASA, sex, age. PEG Polyethylene glycol; PICO Sodium picosulfate; vs Versus

There were no differences in complete colonoscopy rates (intubation of cecum) as a result of bowel cleanliness (95.4\% versus 97.1\%; $\mathrm{P}=0.2$ ), in the adequate and inadequate cleanliness group, respectively.

Mean withdrawal time was, however, significantly shorter in the adequate versus inadequate cleanliness group (difference 1.2 $\pm 0.5 \mathrm{~min}$; absolute times: $8.4 \pm 4.1 \mathrm{~min}$ versus $9.6 \pm 6.3 \mathrm{~min}(\mathrm{P}=0.03)$.

\section{DISCUSSION}

Our study reflects actual practice at a large academic institution participating in population screening for CRC. The major findings are that quality of preparation meets the standardized quality threshold of $90 \%$ in screening examinations. PEG is the most commonly used product and appears to be superior to $\mathrm{PICO}$ in terms of cleansing effectiveness in a screening setting, even after adjustment for potential confounding. Additionally, regardless of the type of product used, split dosing achieved more satisfactory cleansing results but it was not yet the preferred method of colon cleansing at MUHC-MGH, with a very low rate of utilization in 2013. Use of adjuvants only improved bowel cleansing when using PICO; however, there were low rates of lowvolume PEG preparation use. PDR was high but was not associated with the quality of the preparation. PDR was highly correlated with withdrawal time. These results remain very pertinent, even in an era of split-dosing preference, and appropriate predominance because a large proportion of patients endoscoped before 10:30 refuse to get up early to take the second of a split-dose regimen at MGH-MUHC (personal communication, Dr AN Barkun, Montreal, Quebec).

For years, PEG products have been proven safe and efficacious (7) and may be the ideal current preparation, with low side effects. However, the large volume (4 L) and the salty taste impinge on compliance and effectiveness of cleansing, representing barriers to performing successful colonoscopy in healthy individuals, particularly in a screening setting (22). In an effort to improve patient compliance, a reduced-volume lavage regimen comprised of $2 \mathrm{~L}$ of PEG plus four tablets of bisacodyl has been introduced, with conflicting results on efficacy in comparison with high-volume PEG $(5,23)$. A recent metaanalysis concluded that data remain lacking to confidently conclude as to the comparative role of low-volume PEG preparations (24).

As an alternative to PEG products, PICO became an interesting lower volume, better tasting alternative. High patient acceptability and preference have contributed to its wide adoption across the country over the past 10 years (12). However, inconsistent results exist as to its relative efficacy $(13,25,26)$. Our study revealed that the likelihood of achieving adequate bowel cleansing was lowest with PICO compared with PEG, both in the overall colonoscopy population and in those procedures performed solely in the screening setting. This result is consistent with studies performed in the United Kingdom $(14,27)$. More recent randomized controlled trials also compared PEG with PICO. When administered as a day-before preparation, bowel cleansing by $\mathrm{PICO}$ was noninferior compared with PEG, with more favourable tolerance (28-30). Of note, these results differ from our study because the PEG regimen utilized as comparator was systematically a low-volume regimen with an adjuvant administered the day before the colonoscopy. When compared with 4 L PEG 
TABLE 4

Independent predictors of inadequate bowel preparation overall

\begin{tabular}{lcc}
\hline & $\begin{array}{c}\text { Multivariable analysis* } \\
\text { OR }(95 \% \text { Cl) }\end{array}$ & P \\
\hline Bowel preparation & & \\
PEG & 1.00 (reference) & $<0.01$ \\
PICO versus PEG & $4.0(2.7-6.1)$ & $<0.01$ \\
Split regimen & $0.1(0.05-0.5)$ & 0.6 \\
Age $>75$ years & $0.9(0.5-1.5)$ & 0.2 \\
Male sex & $0.8(0.6-1.1)$ & \\
ASA score & - & $<0.01$ \\
Inpatient & $2.8(1.4-5.6)$ & \\
Indication for colonoscopy & & \\
$\quad$ Screening & $1.00($ reference $)$ & 0.2 \\
Follow-up & $1.4(0.8-2.4)$ & $<0.01$ \\
Bleeding & $2.3(1.4-3.8)$ & $<0.01$ \\
Bowel habits modification & $2.2(1.2-3.9)$ & 0.8 \\
Inflammatory bowel disease & $1.1(0.4-3.0)$ & $<0.01$ \\
Others & $3.0(1.7-5.3)$ & \\
\hline
\end{tabular}

${ }^{*}$ Adjusted for all variables listed in the table. ASA American Society of Anesthesiology; PEG Polyethylene glycol; PICO Sodium picosulfate

\section{TABLE 5}

Independent predictors of inadequate bowel preparation in a screening setting

\begin{tabular}{lcc}
\hline & $\begin{array}{c}\text { Multivariable analysis* } \\
\text { OR }(95 \% \mathrm{CI})\end{array}$ & $\mathbf{P}$ \\
\hline Bowel preparation & & \\
Polyethylene glycol & 1.00 (reference) & - \\
Sodium picosulfate & $7.4(4.3-12.6)$ & $<0.01$ \\
Age $>75$ years & $1.8(0.7-4.2)$ & 0.2 \\
Male sex & $1.3(0.8-2.3)$ & 0.3 \\
ASA score & $1.3(0.7-2.1)$ & 0.4 \\
\hline
\end{tabular}

${ }^{*}$ Adjusted for all variables listed in the table. ASA American Society of Anesthesiology

in a split-dose regimen, PICO appears to be less effective and may not offer clear advantages, at least in a non-split-dose regimen (31). Results of a recent meta-analysis show a trend toward benefit for PEG versus PICO without reaching statistical significance (5). Absence of information regarding the amount of PEG administered and patient's tolerance in our study precludes any firm conclusion as to a direct comparison between PEG low volume and PICO preparations. In our study, use of adjuvants only improved bowel cleansing when using PICO. A randomized control trial suggested that PICO associated with bisacodyl provides enhanced colon cleansing compared with PICO alone (11). PICO appears, therefore, acceptable especially if used with adjuvant such as bisacodyl.

European and American guidelines suggest splitting the dose to increase bowel cleanliness and tolerance $(17,18)$. Interestingly, our observational data showed that the endoscopy department at MUHC-MGH had not yet adopted the widespread use of split-dose regimens. In fact, only $5 \%$ of bowel preparations were administrated in a split regimen between April 2013 and April 2014. However, even in our data, split-dose regimens (particularly with PEG) achieved significantly greater proportions of patients with adequate preparations, emphasizing the increased efficacy attributable to a decreased runway time and the greater cleansing ability of PEGbased preparations (16). As a continuous total quality management process, this information has been transmitted to all endoscopists at MUHC-MGH to alter practice accordingly, and adherence to the unit recommendations of split dosing, at least for patients colonoscoped after 10:30, is being enforced more strictly. The diffusion of
TABLE 6

Independent predictors of polyp detection rate overall

\begin{tabular}{|c|c|c|c|c|}
\hline & $\begin{array}{l}\text { Univariable } \\
\text { analysis } \\
\text { OR }(95 \% \mathrm{Cl})\end{array}$ & $\mathbf{P}$ & $\begin{array}{c}\text { Multivariable } \\
\text { analysis* } \\
\text { OR }(95 \% \mathrm{Cl})\end{array}$ & $\mathbf{P}$ \\
\hline Quality of preparation & $1.3(0.9-1.6)$ & 0.2 & $1.2(0.8-1.8)$ & 0.5 \\
\hline Age $>75$ years & $1.6(1.3-2.0)$ & $<0.01$ & $1.7(0.9-3.0)$ & 0.06 \\
\hline Male sex & $1.7(1.5-2.0)$ & $<0.01$ & $1.2(0.8-1.8)$ & 0.3 \\
\hline ASA score & $1.2(1.1-1.4)$ & $<0.01$ & $1.5(1.1-2.2)$ & 0.02 \\
\hline Inpatient & $1.0(0.7-1.5)$ & 0.9 & $0.5(0.2-1.5)$ & 0.3 \\
\hline \multicolumn{5}{|c|}{ Indication of colonoscopy } \\
\hline Screening & 1.00 (reference) & - & 1.00 (reference) & - \\
\hline Follow-up & $1.8(1.4-2.2)$ & $<0.01$ & $1.7(1.0-2.7)$ & 0.04 \\
\hline Bleeding & $0.8(0.6-0.9)$ & 0.01 & $0.6(0.4-1.0)$ & 0.05 \\
\hline \multirow{2}{*}{$\begin{array}{l}\text { Bowel habits } \\
\text { modification }\end{array}$} & $0.6(0.4-0.8)$ & $<0.01$ & $0.5(0.3-0.9)$ & 0.04 \\
\hline & $0.2(0.1-0.4)$ & $<0.01$ & $0.3(0.1-0.8)$ & 0.02 \\
\hline IBD & $0.7(0.5-0.9)$ & 0.02 & $0.7(0.4-1.3)$ & 0.3 \\
\hline \multicolumn{5}{|l|}{ Others } \\
\hline $\begin{array}{l}\text { Withdrawal time } \\
\text { (>6 min) }\end{array}$ & $2.9(2.2-3.9)$ & $<0.01$ & $2.8(1.9-4.2)$ & $<0.01$ \\
\hline
\end{tabular}

${ }^{*}$ Adjusted for all variables listed in the table. ASA American Society of Anesthesiology; IBD Inflammatory bowel disease

TABLE 7

Independent predictors of polyp detection rate in screening setting

\begin{tabular}{lcccc}
\hline & $\begin{array}{c}\text { Univariable } \\
\text { analysis } \\
\text { OR }(\mathbf{9 5 \%} \mathbf{~ C l})\end{array}$ & P & $\begin{array}{c}\text { Multivariable } \\
\text { analysis* } \\
\text { OR } \mathbf{( 9 5 \% ~} \mathbf{~ C l})\end{array}$ & P \\
\hline Quality of preparation & $1.4(0.8-2.2)$ & 0.2 & $1.3(0.5-2.9)$ & 0.5 \\
Age $>75$ years & $2.0(1.2-3.3)$ & $<0.01$ & $1.4(0.3-6.7)$ & 0.6 \\
Male sex & $1.8(1.4-2.3)$ & $<0.01$ & $1.1(0.5-2.1)$ & 0.8 \\
ASA score & $0.9(0.6-1.1)$ & 0.2 & $1.6(0.8-3.1)$ & 0.1 \\
Withdrawal time (>6 min) & $3.2(1.9-5.4)$ & $<0.01$ & $3.3(1.7-6.6)$ & $<0.01$ \\
\hline${ }^{*}$ Adjusted for all variables & listed in the table. ASA American Society of \\
Anesthesiology & &
\end{tabular}

the European and American guidelines on bowel cleansing should further enhance this practice $(17,18)$.

The PDR was high (43.8\%), and even higher in the screening setting (45.6\%), meeting international targets because PDR is a close and reliable proxy of adenoma detection rate $(32,33)$. Intriguingly, the quality of preparation was not associated with the PDR in contrast to results from a previous multicentre European study (34). Reasons for this are unclear but may reflect, in part, varying operator expertise and differing patient characteristics. Of note, cleansing quality in the European study was based on three categories and authors used lowquality cleansing as the reference category. Because endoscopists at the MUHC-MGH do not always adopt the recommended PQDCCR reporting terminology to express the quality of preparation, we dichotomized cleansing quality by grouping excellent or good bowel into adequate preparation versus fair and poor classifications as inadequate - paralleling the actual repeat colonscopy interval recommendation as put forth by the US MSTF (18). Therefore, we cannot determine the impact of poor preparation versus others, which may also explain, in part, the discrepancy in our results. Additionally, the detection of histopathologically confirmed cancer was not significantly compromised by poorly prepared examinations in the European work (34). In another United States study, inadequate preparation quality hindered the detection of small polyps only, while there was no association between quality of the preparation and the detection of significant polyps ( $>9 \mathrm{~mm}$ ) (35). Size and histopathological characteristics of polyps detected at MUHC-MGH were not accessible for the present study, precluding any conclusion. 
The sole independent predictor of polyp detection in our study was withdrawal time. Polyp detection was greater for endoscopists with an average withdrawal time exceeding $6 \mathrm{~min}$, which is consistent with reports from experts, who recommend that the withdrawal phase, exclusive of time for biopsy and polypectomy, should average at least 6 $\mathrm{min}$ to $10 \mathrm{~min}$ (32). Prevalence rates of polyps varied among screening centres and appeared to be higher for examiners spending more time performing the examination $(32,36)$. Our study establishes a strong association between withdrawal time and PDR even after adjustment for quality preparation and should prompt endoscopists to follow this recommendation. However, endoscopists face enormous pressures to increase efficiency by decreasing colonoscopy procedure time. In addition, some question the definition of withdrawal time and its use as as quality indicator (37).

The PQDCCR has developed recommendations to monitor the technical performance of colonoscopy and for continuous quality improvement in colonoscopy (38). A recent audit assessing the quality of reports at MGH-MUHC suggested documentation of these indicators in everyday practice remained incomplete in a small series (39). In our study, quality indicators of the procedure were adequately documented in comparison with this recent audit, mainly the preprocedure indicators. However, the quality of the bowel preparation was not recorded in $40 \%$ of the reports in our analysis. The reason for this may be selection bias in the initial report, coupled with the recent adoption of a scoring system that is more difficult to use. This group without bowel cleansing data was slightly different, mainly in terms of colonoscopy indication (bleeding), hospital setting (inpatient), use of preparation type (PICO was more utilized) and split-dose regimen. We can only make the assumption that endoscopists are aiming at least to document quality indicators, and do not have time to split the dose in certain circumstance such as inpatient bleeding. The fact that PICO was used more often in situations may skew definitive conclusion on its efficacy.

\section{Study limitations and strengths}

The present study provides very important data for the Quebec Ministry of Health in the future deployment of the PDRCC because it provides a snapshot of contemporary bowel cleansing products in an unselected population and in a real-life setting. Strengths include its large sample size, real-life setting and use of a validated electronic data-capturing software (20). The separate assessment among patients for screening and nonscreening indications, among in- and outpatient settings, and the careful analyses of bowel preparation information and quality indicators using a priori defined multivariable analyses are all strengths of the present analysis.

The generalizability of these results (to other countries and secondary or primary hospitals) may be a limitation of the study, particularly for non-Caucasian and for-profit practice environments. Besides, inherent in observational research, such as the present study, is the potential for confounding. Despite adjustment for a range of known and potential confounding variables, we cannot exclude the possibility that our findings can partly be accounted for by residual confounding. In particular, more specific data regarding mode of administration (low versus high volume), differences in timing of colonoscopy, dietary and hydration instructions, and patient support may all contribute to variability in outcomes.

In addition, the present study, similar to all audits, was dependent on the accuracy with which the colonoscopists recorded information into the completed electronic report, with a risk of information bias that was at least partially overcome by the local presence of a research assistant who identified the endoscopic reports and validated the accuracy of information.

However, more than one-half of our patients did not have the bowel preparation type documented and, thus, were initially excluded. In addition, a large group of patients were missing quality-of-bowelcleansing data, reflecting the difficulty to disseminate quality indicators in everyday practice. Furthermore, electronic records unfortunately did not report information on patient tolerance of the preparation; this information is critical for screening programs because it may affect the acceptability of colonoscopy by healthy individuals and the uptake of colonoscopy in screening programs, also precluding firm conclusions regarding patient tolerance among different products. We hope that the results of our study and the future deployment of the PQDCCR may act as catalyst for quality improvement in colonoscopy by facilitating an automatic computerized data collection infrastructure. Even with a computerized endoscopic report generator, documentation of some key quality fields is still not optimal. Preformatted text with compulsory fields and drop-down menus embedded in the electronic reporting system should facilitate reporting.

\section{CONCLUSION}

To standardize and optimize bowel cleansing, we recommend using a split-dose regimen as much as possible for the full deployment of PQDCCR; the use of a split-dose regimen, irrespective of bowel preparations, yielded significantly greater proportions of patients with clean bowels. Endoscopists should then been informed and encouraged to use a split-dose regimen, and this practice monitored. PICO alone appeared to be less effective than PEG in a non-split-dose regimen, such as in our study. However, PICO would be an alternative, particularly if repeated examination will be required, with use of an adjuvant.

Head-to-head in randomized comparisons between PEG and PICO with different modes and timing of administration (high volume, low volume, split-dose regimen according timing of colonoscopy) are lacking. Further comparative studies are warranted to accurately determine the relative efficacy of these two colorectal cleansing agents before colonoscopy, particularly in a screening setting. The true role of adding an adjuvant to PICO compared with PEG also warrants further study.

DISCLOSURES: The authors have no financial disclosures or conflicts of interest to declare.

\section{REFERENCES}

1. International Agency for Research on Cancer. GLOBOCAN 2012: Estimated Cancer Incidence, Mortality and Prevalence Worldwide in 2012. <http://globocan.iarc.fr> (Accessed December 13, 2013).

2. Leddin DJ, Enns R, Hilsden R, et al. Canadian Association of Gastroenterology position statement on screening individuals at average risk for developing colorectal cancer: 2010. Can J Gastroenterol 2010;24:705-14.

3. Jemal A, Bray F, Center MM, Ferlay J, Ward E, Forman D. Global cancer statistics. CA Cancer J Clin 2011;61:69-90.

4. Edwards BK, Ward E, Kohler BA, et al. Annual report to the nation on the status of cancer, 1975-2006, featuring colorectal cancer trends and impact of interventions (risk factors, screening, and treatment) to reduce future rates. Cancer 2010;116:544-73.

5. Belsey J, Crosta C, Epstein O, et al. Meta-analysis: The relative efficacy of oral bowel preparations for colonoscopy 1985-2010. Aliment Pharmacol Ther 2012;35:222-37.

6. Hookey LC, Depew WT, Vanner S. The safety profile of oral sodium phosphate for colonic cleansing before colonoscopy in adults. Gastrointest Endosc 2002;56:895-902.

7. DiPalma JA, Brady CE III, Stewart DL, et al. Comparison of colon cleansing methods in preparation for colonoscopy. Gastroenterology 1984;86:856-60.

8. Saunders BP, Masaki T, Fukumoto M, Halligan S, Williams CB. The quest for a more acceptable bowel preparation: Comparison of a polyethylene glycol/electrolyte solution and a mannitol/picolax mixture for colonoscopy. Postgrad Med J 1995;71:476-9.

9. Hangartner PJ, Munch R, Meier J, Ammann R, Buhler H. Comparison of three colon cleansing methods: Evaluation of a randomized clinical trial with 300 ambulatory patients. Endoscopy 1989;21:272-5. 
10. Marshall JB, Pineda JJ, Barthel JS, King PD. Prospective, randomized trial comparing sodium phosphate solution with polyethylene glycol-electrolyte lavage for colonoscopy preparation. Gastrointest Endosc 1993;39:631-4.

11. Hookey LC, Vanner SJ. Pico-salax plus two-day bisacodyl is superior to pico-salax alone or oral sodium phosphate for colon cleansing before colonoscopy. Am J Gastroenterol 2009;104:703-9.

12. Love J, Bernard EJ, Cockeram A, et al. A multicentre, observational study of sodium picosulfate and magnesium citrate as a precolonoscopy bowel preparation. Can J Gastroenterol 2009;23:706-10.

13. Hoy SM, Scott LJ, Wagstaff AJ. Sodium picosulfate/magnesium citrate: a review of its use as a colorectal cleanser. Drugs 2009;69:123-36.

14. Dakkak M, Aziz K, Bennett JR. Short report: Comparison of two orally administered bowel preparations for colonoscopy polyethylene glycol and sodium picosulphate. Aliment Pharmacol Ther 1992;6:513-9.

15. Connor A, Tolan D, Hughes S, Carr N, Tomson C. Consensus guidelines for the safe prescription and administration of oral bowel-cleansing agents. Gut 2012;61:1525-32.

16. Cohen LB. Split dosing of bowel preparations for colonoscopy: An analysis of its efficacy, safety, and tolerability. Gastrointest Endosc 2010;72:406-12.

17. Hassan C, Bretthauer M, Kaminski MF, et al. Bowel preparation for colonoscopy: European Society of Gastrointestinal Endoscopy (ESGE) guideline. Endoscopy 2013;45:142-50.

18. Johnson DA, Barkun AN, Cohen LB, et al. Optimizing adequacy of bowel cleansing for colonoscopy: Recommendations from the US multi-society task force on colorectal cancer. Gastroenterology 2014; 147:903-24.

19. Rex DK, Imperiale TF, Latinovich DR, Bratcher LL. Impact of bowel preparation on efficiency and cost of colonoscopy. Am J Gastroenterol 2002;97:1696-700.

20. Beaulieu D, Martel M, Barkun AN. A prospective intervention study of colonoscopy reporting among patients screened or surveilled for colorectal neoplasia. Can J Gastroenterol 2012;26:718-22.

21. Aronchick CA, Lipshutz WH, Wright SH, Dufrayne F, Bergman G. A novel tableted purgative for colonoscopic preparation: Efficacy and safety comparisons with Colyte and Fleet Phospho-Soda. Gastrointest Endosc 2000;52:346-52.

22. Senore C, Ederle A, Fantin A, et al. Acceptability and side-effects of colonoscopy and sigmoidoscopy in a screening setting. J Med Screen 2011;18:128-34.

23. DiPalma JA, Wolff BG, Meagher A, Cleveland M. Comparison of reduced volume versus four liters sulfate-free electrolyte lavage solutions for colonoscopy colon cleansing. Am J Gastroenterol 2003;98:2187-91.

24. Ménard C, Barkun AN, Martel M, Restellini S, Kherad O. A metaanalysis of colon cleansing with PEG compared to other bowel preparations. Gastrointest Endosc 2104;79(Suppl):AB319.

25. Barkun A, Chiba N, Enns R, et al. Commonly used preparations for colonoscopy: Efficacy, tolerability, and safety - a Canadian Association of Gastroenterology position paper. Can J Gastroenterol 2006;20:699-710.
26. Kao D, Lalor E, Sandha G, et al. A randomized controlled trial of four precolonoscopy bowel cleansing regimens. Can J Gastroenterol 2011;25:657-62.

27. Worthington J, Thyssen M, Chapman G, Chapman R, Geraint M. A randomised controlled trial of a new 2 litre polyethylene glycol solution versus sodium picosulphate + magnesium citrate solution for bowel cleansing prior to colonoscopy. Curr Med Res Opin 2008;24:481-8.

28. Katz PO, Rex DK, Epstein M, et al. A dual-action, low-volume bowel cleanser administered the day before colonoscopy: Results from the SEE CLEAR II study. Am J Gastroenterol 2013;108:401-9.

29. Manes G, Amato A, Arena M, Pallotta S, Radaelli F, Masci E. Efficacy and acceptability of sodium picosulphate/magnesium citrate vs low-volume polyethylene glycol plus ascorbic acid for colon cleansing: A randomized controlled trial. Colorectal Dis 2013;15:1145-53.

30. Rex DK, Katz PO, Bertiger G, et al. Split-dose administration of a dual-action, low-volume bowel cleanser for colonoscopy: The SEE CLEAR I study. Gastrointest Endosc 2013;78:132-41.

31. Voiosu T, Ratiu I, Voiosu A, et al. Time for individualized colonoscopy bowel-prep regimens? A randomized controlled trial comparing sodium picosulphate and magnesium citrate versus 4-liter split-dose polyethylene glycol. J Gastrointestin Liver Dis 2013;22:129-34.

32. Rex DK, Bond JH, Winawer S, et al. Quality in the technical performance of colonoscopy and the continuous quality improvement process for colonoscopy: Recommendations of the U.S. Multi-Society Task Force on Colorectal Cancer. Am J Gastroenterol 2002;97:1296-308.

33. Williams JE, Holub JL, Faigel DO. Polypectomy rate is a valid quality measure for colonoscopy: Results from a national endoscopy database. Gastrointest Endosc 2012;75:576-82.

34. Froehlich F, Wietlisbach V, Gonvers JJ, Burnand B, Vader JP. Impact of colonic cleansing on quality and diagnostic yield of colonoscopy: The European Panel of Appropriateness of Gastrointestinal Endoscopy European multicenter study. Gastrointest Endosc 2005;61:378-84.

35. Harewood GC, Sharma VK, de Garmo P. Impact of colonoscopy preparation quality on detection of suspected colonic neoplasia. Gastrointest Endosc 2003;58:76-9.

36. Butterly L, Robinson CM, Anderson JC, et al. Serrated and adenomatous polyp detection increases with longer withdrawal time: Results from the New Hampshire Colonoscopy Registry. Am J Gastroenterol 2014;109:417-26.

37. Moritz V, Bretthauer M, Ruud HK, et al. Withdrawal time as a quality indicator for colonoscopy - a nationwide analysis. Endoscopy 2012;44:476-81.

38. Barkun A. Normes de pratique clinique relatives à la coloscopie. Direction québécoise du cancer. Mars 2012. <www.msss.gouv.qc.ca/ professionnels/pqdccr/documents/normes_cliniques_mars_2012.pdf> (Accessed January 21, 2015).

39. Beaulieu D, Barkun A, Martel M. Quality audit of colonoscopy reports amongst patients screened or surveilled for colorectal neoplasia. World J Gastroenterol 2012;18:3551-7. 


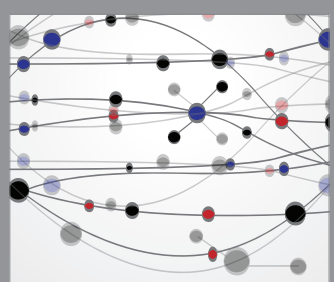

The Scientific World Journal
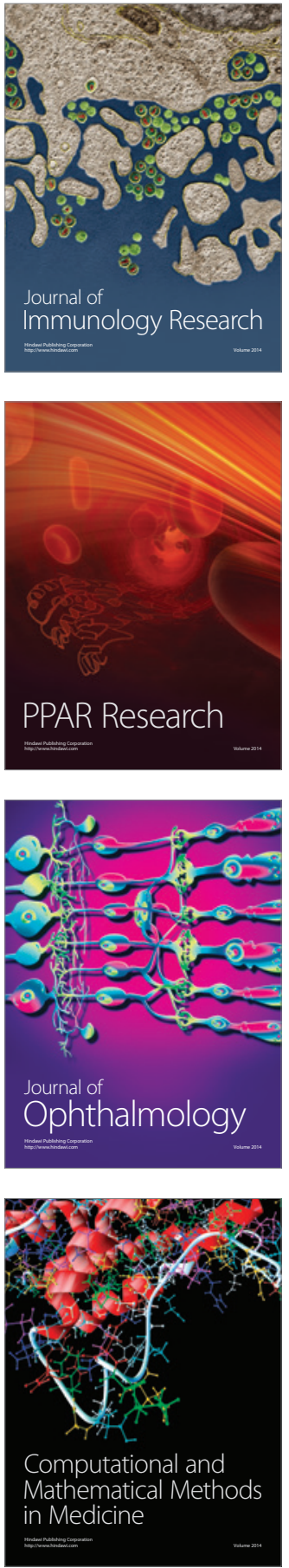

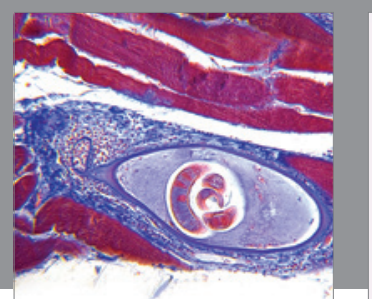

Gastroenterology Research and Practice

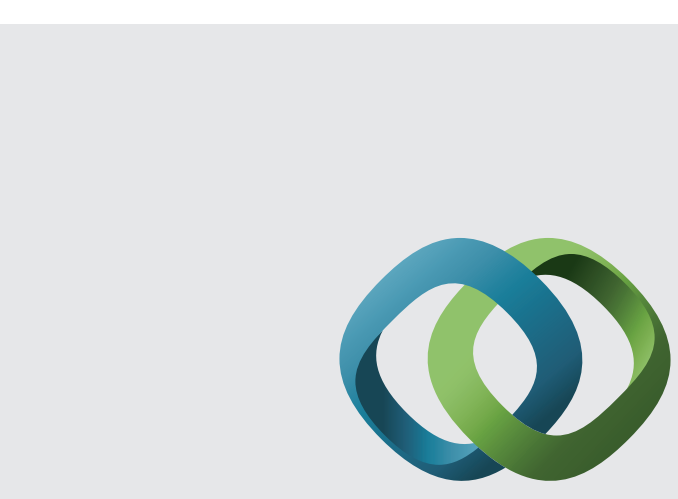

\section{Hindawi}

Submit your manuscripts at

http://www.hindawi.com
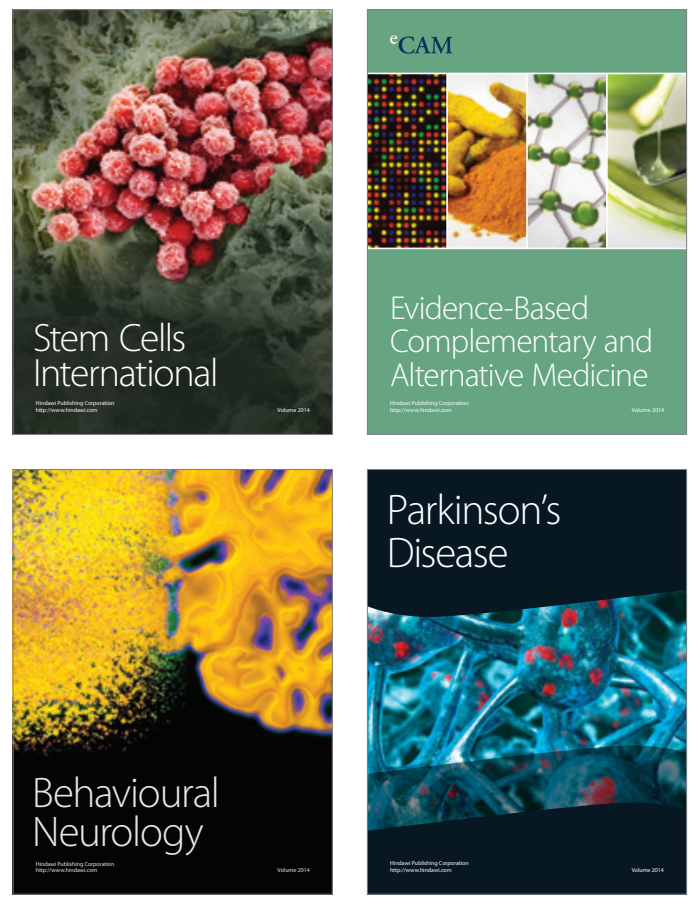
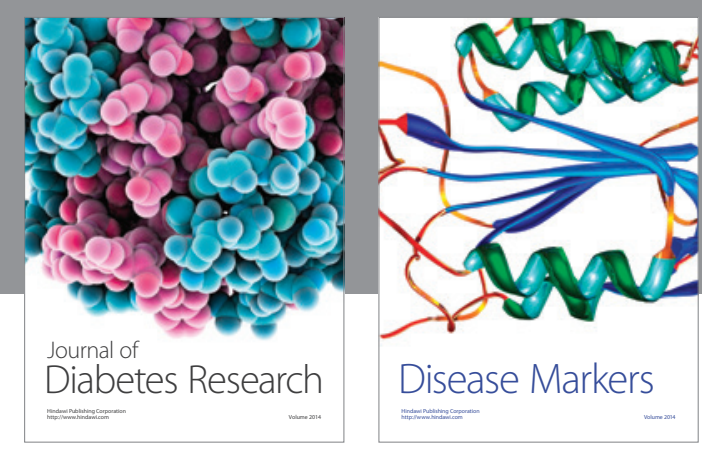

Disease Markers
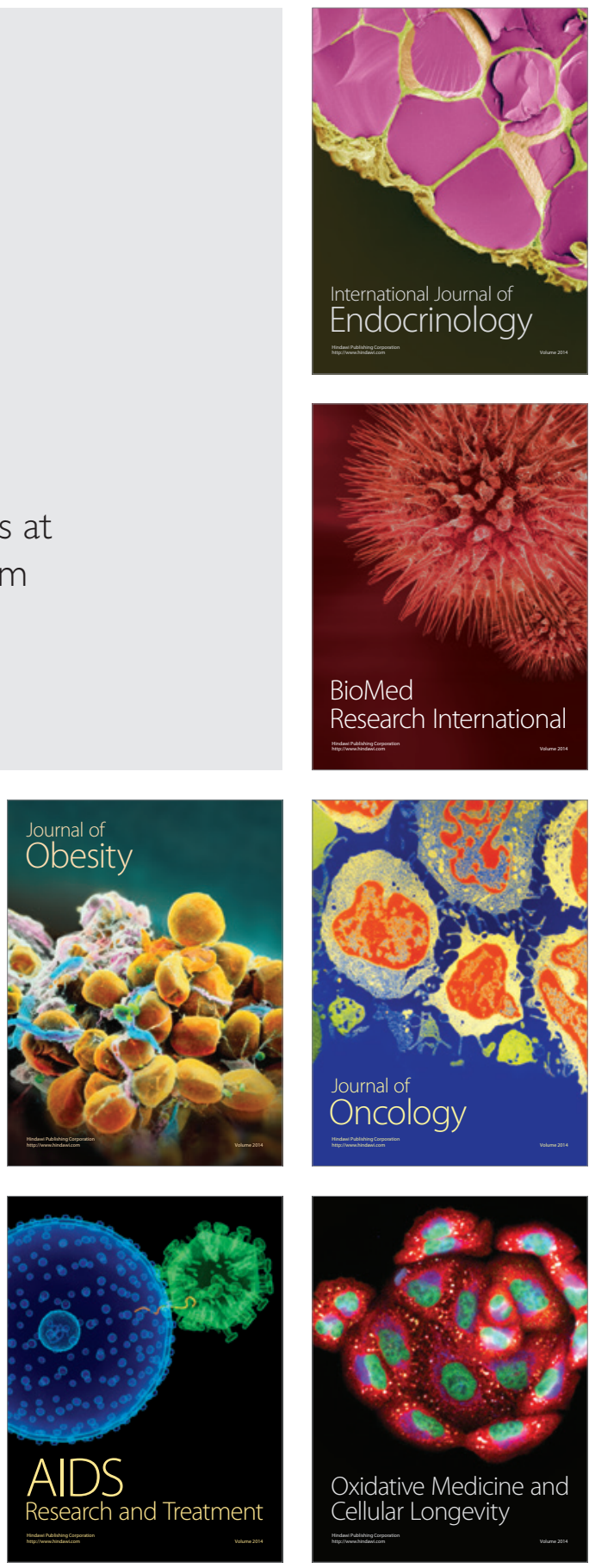